\title{
The Effectiveness of Computer-Based Problem Solving to Improve Higher Order Thinking Skills on Prospective Teachers
}

\author{
Yurniwati \\ Jakarta State University, Indonesia,yurniwati@unj.ac.id \\ Dudung Amir Soleh \\ Jakarta State University, Indonesia, dudung@unj.ac.id
}

Computer-Based Problem Solving is a combination of problem-based learning and computer-assisted learning. The method facilitates students to use computer programs as cognitive tools to solve problems. The purpose of this study is to determine the effect of Computer Based Problem Solving on High Level Thinking Skills (HOTS) of prospective teachers. The study was conducted in the 5th semester of the 2018/2019 academic year. This is a quasi-experiment with pre-test and post-test control group design consist. In the process of learning, the experimental group used computer-based problem solving as treatment whereas the control gorup used traditional methods. HOTS data was collected by conducting essay tests and the data was analyzed by using t-test and ANOVA. The findings of this study revealed that using computer-based problem solving approach improved HOTS of the prospective teachers as well as enhance their collaboration and motivation. It was found out that there was a moderate improvement on HOTS aspects in communication. The study also showed very slight improvement on the prospective teacher's problem solving abilities.

Keywords: computer-based problem solving, HOTS, thinking skills, prospective teachers, computer-assisted learning

\section{INTRODUCTION}

In this global era, developing students' 21 st century skills has been the great concern of many educators. The $21^{\text {st }}$ century education includes problem solving, critical thinking and higher-order thinking (Higgins, 2014; Kivunja, 2014; Soule \& Warrick, 2015), specifically in academia and the workplace (Lee \& Choi, 2017). The effect of HOTS on learning outcomes is the ability to obtain information through active learning such as exploration, discovery and experimentation. Students who have HOTS are able to access information to use new contexts and easily transfer knowledge into different situations (Mainali, 2012). While the influence of HOTS on work is mainly to obtain information, 
however, the most important point is how to manage, analyze, criticize and change acquired information into useful knowledge (van Laar at al., 2017). For example as a teacher, it is intended to design appropriate, effective and efficient learning including the learning methods, learning tools, and assessment. Teachers are required to be able to analyze appropriate teaching methodologies to specifie content areas, identify learning tools to support learning, develop student reasoning and problem solving abilities. According to Yen \& Halili (2005) HOTS is an indispensable skill for every individual in any educational environment.

At present, many definitions have been proposed by experts on high-order thinking. Since 1987, Resnick has argued that high-level thinking is characterized by the following characteristics: not algorithmic, complex, multi-solution, involving decision making and interpretation, application of various criteria, often uncertainty, selfregulation, looking for flawed structures. HOTS is the ability to apply facts to new situations (Moursund, 2003). Similar opinion was also conveyed by Vui (2007) that high-level thinking skills will occur if someone associates new information with information that has been stored in his memory and connects it or rearranges and develops that information to achieve the goal. Zoller \& Pushkin (2007) used High Level Cognitive Skills (HLCS) instead of HOTS. They argue that the HLCS has enhanced students' problem solving, decision making and critical thinking skills development. High-level thinking is compiling arguments, asking questions, making comparisons, resolving non-routine problems (Zohar \& Dori, 2009). Yang (2015) identifies creative and critical thinking and problem solving as high-level thinking. Yen and Halili (2015) also characterize high-level thinking: (a) not routine / not fully known beforehand, (b) complex, (c) produce various solutions/points of view, (d) involving uncertainty, (e) Involving the process of making meaning, (f) Need effort, requires mental work. All HOTS definitions emphasize on non-routine problems, knowledge construction, requires considerable effort.

In mathematics, Webb \& Coxford as quoted in Sumarmo \& Nishitani (2010) states that in mathematics, the ability to understand ideas is implied; compile guesses, analogies and generalizations; logical reasoning, solving problems; communicate mathematically; associating mathematical ideas with other intellectual activities belong to the HOTS aspect. In other words, HOTS in mathematics is reasoning, Mathematical connection, mathematical communication and problem solving. NCTM (2000) identified problem solving is students create new mathematical knowledge that arise in mathematics and other contexts. Reasoning include apply various types of reasoning, construct conjectures and mathematical arguments. Mathematical communication as tool to express mathematical ideas, and analyze mathematical thinking of others. Mathematical connection provides understanding the way mathematical ideas interrelate and build on one another. If students are faced with problem solving, students will think of the information in the problem and connect it with the concept which is the basis to answer the problem. From these conditions, strategies are developed to solve problems and communicate in the form of equations, drawings, charts, etc. 
On the other hand, according to Newman and Wehlage (2003) lower Order Thinking Skills (LOTS) restate facts or apply rules and algorithms through routine problems. As recipients of information, students are given knowledge from simple concepts to complex. Students in this case repeat the knowledge that has been received to answer memory questions. LOTS occurs because in the learning process, students do not get the opportunity to develop thinking skills and actively acquire knowledge. In addition, students are also not challenged with open questions and non-routine problems.

There are two categories of HOTS, namely high-order thinking in scientific disciplines and general high-order thinking skills (Resnick, 1987). General high-order thinking skills are special classes that emphasize that high-order thinking skills can be transferred among subjects. High-order thinking in subjects leads to the integration of high-order thinking skills and techniques in subjects.

Fisher (in Puchta, 2012) argues "thinking does not occur naturally and needs to be developed". This means that it is necessary for student to undergo continuous practice to be able to think at a high level. Rajendaran (2000) argues similarly that thinking is not automatic, but can be learned. The Department for Education and Skill (DfES, 2005) suggests that learning activities that can enhance high-level thinking skills are: (1) students work collaboratively in groups, (2) resolve problems, (3) carry out activities that can accommodate different learning styles, (4) develop different thinking skills (such as analysis, synthesis, creative, inductive, deductive, divergent and convergent).

One learning approach that meets the learning criteria described above is problem-based learning. Bay (in Shinn et al., 2003) explains problem-based learning in mathematics is to teach knowledge and skills in the form of problem solving. Problems are presented as contexts and stimuli for learning. According to Liu (2005) problem-based learning has essential characteristics such as the following: (1) Student-cantered learning; (2) Forms of authentic problems that direct the focus of learning; (3) New information is obtained through self-directed learning; (4) Learning takes place in small groups, and (5) The teacher acts as a facilitator.

Along with the development of technology rapidly, the way of teaching and learning are changing accordingly. Technology, which has directly changed the way of interacting, communicating, studying and investigating (Pescador, 2014). Also, the students mode of learning change from passive learning becoming active learning, working in groups interacting through computer technology to think critically to find solution of problems (Henderson, 2017). Similar to Jonassen and Car (2000) who discussed learning by using technology from a constructivist perspective. They advocate the use of computers as a cognitive tool for constructing and facilitating the learning of high-level thinking skills. Besides, the role of computers in learning include support "internal negotiation" and understand meaning, concept representation construction and support logical thinking (Bukar, Bello, \& Ibi, 2016).

Consider the role of computer as logical thinking development, Ekstig (2004) suggested to combine computer technology and problem solving namely Computer-Based Problem Solving (CBPS). CBPS places students as learning centres using software tools to construct, investigate, represent, implement during the problem solving process. Santos 
at al. (2003) suggested students need to use different representational media to express their ways of thinking while dealing with tasks or problems. The use of different tools offers students the possibility of examining situations from perspectives that involve the use of various concepts and resources. Thus, during this process, specially dynamic constructions help students focus their attention on common properties that appear while moving elements within the same configuration or representation. It provide the opportunity to implement techniques and tools that are not obtainable in a paper-pencil environment in the investigation of mathematical problems (Arcavi \& Hadas, 2000; Çekmez \& Bülbül, 2018).

In relation with the learning process, Passey at al. (2000) divides it into three parts, namely: internalization, internal cognition and externalization. Internalization is explained through a process related to involvement and attention. Internal cognition is a process relating to knowledge, understanding, analysis, synthesis, and evaluation. Externalization involves expressing ideas through writing and oral. Integration of technology into mathematics learning specifically reaches the three parts to the learning process. Computers are excellent tools in presenting images or diagrams of the right size that attracts students' attention. Visualization provided by computers helps students to explore to build knowledge, find relationships, test, interpret information, design, analyze, synthesize, elaborate, solve problems and take decisions. Finally, the computer helps present what students know to others.

The process of thinking that occurs in internal cognition supported by computer facilities includes high-level thinking. Therefore, technology in learning can be used as a means to engage students actively in constructing knowledge, problem-solving and critical thinking to improve higher-order thinking skills (Jonnasen \& Car, 2000). Furthermore, the role of technology in HOTS in mathematics are: (1) Improving students multi-representation capabilities, (2) facilitating students to understand and develop concepts, (3) improving mathematical reasoning capabilities, (4) engaging students to solve problem; (5) Mathematical communication tools (Kimmins, 2005)

Not all computer technology can be used to enhance high-level student thinking. Glazer (2001) distinguishes computer use in the classroom, namely, computers as a tool for exploration and as a tutor. Computers as a tool of exploration or problem solving will build high-level thinking skills. Instead, using a computer as a tutor, giving instructions and feedback only emphasizes low-level thinking skills.

Some empirical studies related to computer-based learning, beginning with Roh \& Park (2010) conducted a meta-analysis of 27 studies on the effect of Computer-Based Education on nursing students from 1990-2009. They found out that Computer-Based Education has a positive influence on knowledge, attitudes and skills. Larwin \& Larwin (2011) conducted a meta-analysis of the effects of Computer-Assisted Instruction on student statistics. There were studies conducted between 1970-2010. The conclusion of his study was that CAI had a high influence, namely $\mathrm{d}=0,566$ on student learning outcomes in the statistics department. Furthermore, Sung, Yang and Lee (2017) conducted a meta-analysis of the effect of mobile-Computer-Supported Collaborative Learning on group learning effectiveness in 48 journals between 2000-2015. Their 
findings are that mCSCL significantly increases student collaboration with an effect size of 0.516. Sudibyo, Jatmiko, \& Widodo (2016) examined the effectiveness of the Computer-Based Learning (CBL) model to improve students' thinking skills in sports science. The findings of their study were that CBL effectively improved the analytical thinking skills of sports science students by $\mathrm{N}$-gain $=0.78$ and included in the high category.

To put a higher level of previous research results, this study combines Computer-Based Learning with Problem Solving called Computer-Based Problem Solving (CBPS). In applying the CBPS model, learning uses the problem context, and GeoGebra acts as a cognitive tool for solving mathematical problems. GeoGebra is an interactive geometry software founded by Hohenwarter in 2001(Hohenwarter \& Fuchs, 2004). The basic objects in GeoGebra are points, vectors, segments, polygons, straight lines, all conic sections and functions in $x$. GeoGebra as dynamic constructions can be altered dynamically by dragging free objects. Furthermore, it is possible to enter coordinates of points or vectors, equations of lines, conic sections or functions and numbers or angles directly. Hohenwarter \& Fuchs (2004) argued GeoGebra is powerful tool for mathematics education cause: 1) GeoGebra support demonstration and visualisation, 2) GeoGebra has all the abilities which are demanded construction graphics, 2 dimensional and 3 dimensional shapes, etc., 3) GeoGebra contribute in discovering mathematics knowledge and knowledge processing.

\section{Research Question}

The purpose of this study was to determine the effect of CBPS on HOTS of prospective teachers. Specifically, this study aims to find out:

1. Are there a significant differences in the HOTS pre-test of prospective teachers in the two research groups?

2. Is there a significant effect on the HOTS of prospective teachers in the two research groups?

3. Is there a significant effect of HOTS aspect of prospective teachers in the two research groups?

\section{METHOD}

The target population of the study are prospective teachers of primary school in the department of teacher education, faculties of Education at Jakarta State University. The participants are 32 of 160 prospective teachers enrolled in the $5^{\text {th }}$ semester in 2018-2019 Academic Year. In Indonesia, Elementary Teacher Education consist of 6 semesters learning in campus, 2 semesters for field practice and research. They study content knowledge, pedagogical knowledge and 5 subjects matter (Mathematics, Science, Social Studies, Language, Moral Studies). One subject of content knowledge is Basic Mathematics. In Basic Mathematics they learn basic concept of mathematics and problem solving like logic, relation and function, linear equation and quadratic equation.

The research method is a quasi-experimental. The research design was the pre-test-posttest design. Two classes were chosen as research samples, namely the experimental and control groups. The research was conducted for 5 weeks. In this study involved linear 
equation and function. The experimental group and the control class studied the same material and were given the same test. The experimental group's treatment was CBPS while the control group was using expository learning.

\section{Subject Delivery}

Learning begins by giving questions to participants then, they work in groups and do intense discussion to be able to answer the questions. As an illustration, the following are examples of learning activities for linier equation.

1. Make a line through point $\mathrm{A}(0,3)$ and $\mathrm{B}(2,0)$, observe the equation of the line (in the format $a x+b y=c$ )

2. Make a line through $\mathrm{C}(0,5)$ and $\mathrm{D}(4,0)$. Note the equation of the line that appears.

3. Observe the two line equations and relate them to the intersection of the line with the $\mathrm{x}$-axis and $y$-axis.

4. What is the equation if the line is through points $\mathrm{E}(0, \mathrm{a})$ and $\mathrm{F}(\mathrm{b}, 0) 5$. Your conclusion is:

Participants work on steps 1 and 2 on GeoGebra. On the GeoGebra screen it will look like Figure 1.

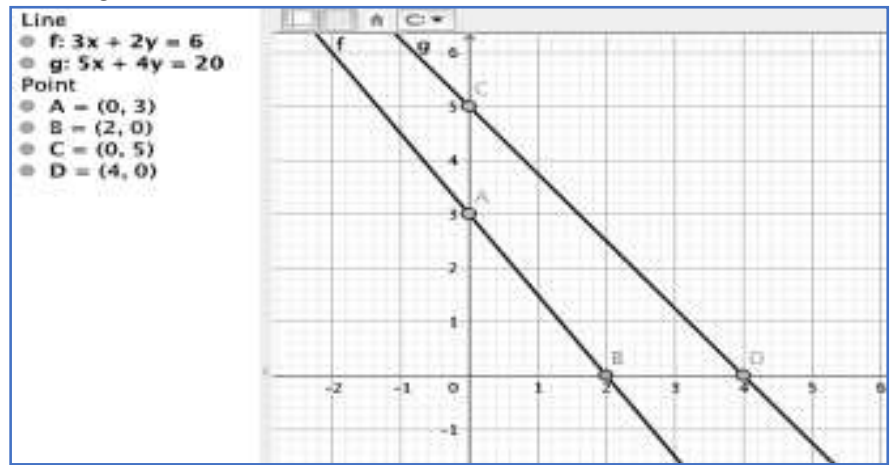

\section{Figure 1}

Graph of $3 x+2 y=6$ and $5 x+4 y=20$

In step 3, participants try to create a function equation based on the results of step 1 and step 2. Participants observe the relationship between the coordinates of the point and the equation of the line on the algebraic screen. In step 1 , the line goes through $A(0,3)$ and $B(20)$ and equals $3 x+2 y=6$. This means that the ordinate point $A$ is the $x$ coefficient and the abscissa point $\mathrm{B}$ is the coefficient $\mathrm{y}$. In step 2 , the line through $\mathrm{C}(0,5)$ and $\mathrm{D}$ $(4,0)$. and the equivalent is $5 x+4 y=20$. Also obtained by the ordinate point $C$ is the $x$ coefficient and the absent point $\mathrm{D}$ is the coefficient $\mathrm{y}$. By paying attention to the ordinate connection and the point abscissa with the line equation, participants can determine the function of the line through $\mathrm{E}(0, \mathrm{a})$ and $\mathrm{F}(\mathrm{b}, 0)$ is $\mathrm{ax}+\mathrm{by}=\mathrm{ab}$.

When participants determine the function equation, participants involve deductive reasoning to formulate function equations. Communicating the mathematical expression 
in of equations, graphs or tables is called mathematical communication. In step 5, participants draw conclusions from the findings obtained based on the overall activity.

While on the control group, participants learn using paper and pencil. To learn the

function equation, the teacher shows a graph that intersects the $\mathrm{x}$-axis and $y$-axis. With the question and answer strategies, participants are directed to observe the relationship of the intersection of line and line equations. As an illustration, the teacher displays a graph in Figure 2.

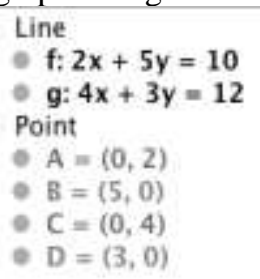

Figure 2

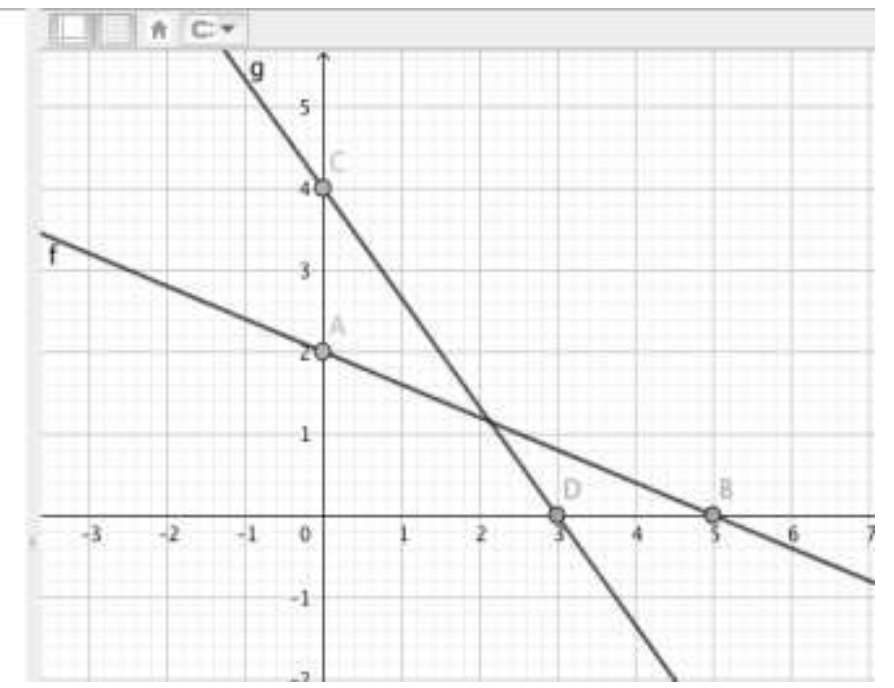

Graph of $2 x+5 y=10$ and $4 x+3 y=12$

Teacher ask questions to participants as follows:

a) Pay attention to the line through point $\mathrm{A}$ and $\mathrm{B}$

b) note the function equation

c) Can you see the relationship between the function equation and the graph intersection with the axis line?

d) Now look at the lines that pass point $\mathrm{C}$ and $\mathrm{D}$

e) Observe the function equation. What is the relationship between the function equation and the intersection point of the line?

f) What is your conclusion?

After the question and answer activities, participants did worksheets and closed by discussing the answers.

The instrument refers to HOTS definition according to Webb \& Coxford, as presented in Table 1. 
Table 1

Instruments

\begin{tabular}{lllll}
\hline Domain & HOTS & & \\
\cline { 2 - 5 } & Reasoning & $\begin{array}{l}\text { Mathematical } \\
\text { Connection }\end{array}$ & $\begin{array}{l}\text { Mathematical } \\
\text { Communication }\end{array}$ & Problem solving \\
\cline { 2 - 5 } Linier Equation & 1 & 1 & 1 & 1 \\
Function & 1 & 1 & 1 & 1 \\
\hline Total & 2 & 2 & 2 & 2 \\
\hline
\end{tabular}

The pre-test and post-test scores were processed according to the research questions. The statistical test used is t-test, ANOVA and Normalized Gain.

\section{FINDINGS}

Table 2

The Pre-Test and Post-Test Scores of Research Groups

\begin{tabular}{llllllll}
\hline Test & Groups & $\mathrm{N}$ & Mean & StDev & Minimum & Median & Maximum \\
\hline Pre-test & Exp. & 18 & 20.222 & 10.050 & 7.000 & 16.500 & 46.000 \\
& Control & 18 & 17.778 & 5.275 & 4.000 & 18.000 & 28.000 \\
Pos-test & Exp. & 18 & 39.444 & 10.799 & 25.000 & 38.500 & 65.000 \\
& Control & 18 & 27.333 & 7.631 & 8.000 & 29.000 & 40.000 \\
\hline
\end{tabular}

Based on Table 2 it is known that there is little difference in the pre-test data between the experimental and control groups. Whereas in the post-test data there was a considerable difference between the experimental and control groups. Descriptively it can be stated that there are differences in HOTS between the experimental class and the control class. In this case the experimental group had HOTS higher than the control group

\section{Research Question 1:}

Table 3

Analysis of the Normality on the Pre-Test Scores on the Experimental and Control Groups

\begin{tabular}{llll}
\hline Group & Anderson Darling -Value & df & P-value \\
\hline Exp. & 0.55 & 17 & 0.1380 \\
Control & 0.45 & 17 & 0.245 \\
\hline
\end{tabular}

Table 3 shows the P-value of Experiment group $=0.1380>0.05$ and the P-value of control group $=0.245>0.05$. This means the pre-test data of both groups is normal distribution

Next, an independent $t$ test was conducted to determine the differences between the two research groups. The results can be seen in Table 3 .

Table 4

Independent Samples T-Test from the Experimental and Control Groups

\begin{tabular}{llll}
\hline Group & T Student -Value & df & P-value \\
\hline Pre-test & 0.914 & 34 & 0,367 \\
\hline
\end{tabular}


In table 4, the results of the Independent Samples T-Test is obtained for the pre-test with $\mathrm{P}$-value $=0.367$, meaning that there is no statistically significant difference in the HOTS initial ability in the experiment and control group. As a result, both groups are feasible to use in the study to compare the two methods.

\section{Research Question 2:}

This section aims to determine whether there are significant HOTS differences between the experimental and control groups after receiving treatment. Statistical tests were carried out with ANOVA test. The normality test and homogeneity test were ppreviously carried out as analysis requirements test.

Table 5

Analysis of the Normality on the Pre-Test Control Groups

\begin{tabular}{llll}
\hline Group & Anderson Darling -Value & df & P-value \\
\hline Exp. & 0.51 & 17 & 0.1749 \\
Control & 0.35 & 17 & 0.4334 \\
\hline
\end{tabular}

Table 5 shows the P-value of Experiment group $=0.1749>0.05$ and the P-value of control group $=0.4334>0.05$ This means the post-test scores of both groups is in Normal distribution. Next, Homogeneity is test carried out using Multiple Comparisons and Levene's.

Table 6

Homogeneity Test on Post-Test

\begin{tabular}{llll}
\hline Method & Test Statistic & df & P-Value \\
\hline Multiple comparisons & 1.21 & 17 & 0.2715 \\
Levene & 1.13 & 17 & 0.2958 \\
\hline
\end{tabular}

Table 6 shows the P-value of Multiple Comparison $=0.2715>0.05$ and the P-value of Levene $=0.2958>0.05$ This means the post-test scores of both groups is homogenous Because the post-test data is normal and homogeneous, then ANOVA test.

Table 7

Analysis of Variance

\begin{tabular}{llllll}
\hline Source & DF & Adj SS & Adj MS & F-Value & P-Value \\
\hline Factor & 1 & 1320.11 & 1320.11 & 15.10 & 0.0004 \\
Error & 34 & 2972.44 & 87.42 & & \\
Total & 35 & 4292.56 & & & \\
\hline
\end{tabular}

Table 7 indicates that $\mathrm{p}$ value $=0.0004<0.05$ is statistically significant the difference of HOTS between Experiment and control group. The post-test mean scores of the experimental group was higher than the post-test mean of the control group. Therefore, it can be concluded that the application of CBPS can increase HOTS of the prospective teachers.

\section{Research Question 3}

This section discusses how improvements have occurred in the HOTS aspect after being treated. As discussed earlier that the aspects of HOTS include Problem Solving, 
Reasoning, connection, Communication. The improvement of HOTS aspect is determined by normalized gain as shown in Table 7 .

Table 7

Average Normalize Gain of HOTS Aspects

\begin{tabular}{lll}
\hline Aspect & N Gain & Level \\
\hline Communication & 0.53 & Moderate \\
Reasoning & 0.41 & Moderate \\
connection & 0.37 & Moderate \\
Problem Solving & 0.24 & Low \\
HOTS & 0.42 & Moderate \\
\hline
\end{tabular}

Based on the table it is known that there is a moderate level increase in all aspects of HOT except problem solving.

\section{DISCUSSION}

The results of the hypothesis test indicate that experimental group obtained a higher HOTS score than the control group because prospective teachers treated by CBPS have better HOTS abilities than conventional learning. Based on problem given, prospective teacher use GeoGebra to explore, investigate causal effect of changing graphic to function equation or vice versa. It was observed that the use of technology helped teachers to develop ways of reasoning and forms of reflecting about the meaning and connections among mathematical objects. For example, the dynamic software enabled teacher to search for various forms of justifying a conjecture, in which the use and integration of visual, empirical and deductive arguments were useful. They grasp similarity and difference until the determinate formula or conclusion. This finding in line with Kuzle (2017) found that Dynamic Software Geometry such as GeoGebra as a cognitive tool that can enhance and reorganize the problem solving process. It allowed and supported prospective teachers to discover new methods of thinking, and inhibited the problem solving processes.

GeoGebra is highly beneficial because it has advantages such as visualization, especially the construction of accurate images and Loci. This founding in line to Doruk at al. (2013) that computer-assisted learning is very helpful in learning process. Similarlly Moreover, technology as a cognitive tool was used to find information, make models and present solutions to improve collaboration, share ideas, motivation and social behaviour (Glazer, 2001). Moreover, Geogebra able perform various mathematical communication in graphs, equation, cartesian coordinate system. It improves prospective teachers understanding on concepts and interconnected between concepts and finally develop conceptual knowledge.

While in conventional learning, prospective teachers gain knowledge about facts, concepts and procedures such as rules and formulas from teachers and source books. Then the knowledge is used to answer repetitive questions and application procedures to routine problems. Doing routine problems continuously makes math work mechanical. As a result, the prospective teacher thinking limited on memorizing, understanding and application (Lower Order Thinking Skills). 
Unlike in conventional learning, the classroom atmosphere in CBPS is dynamic. Prospective teachers are conditioned and engaged in group discussion in an effort to solve problems. The student's deep engagement in activities, occurs because CBPS learning emphasizes not only knowledge but also the skills needed in learning such as problem solving, acquiring knowledge and working together in groups. When prospective teachers work in groups, there seems to be a very good interaction between prospective teachers. They collaborate help each other, appreciate the efforts or opinions of friends and give awards in the form of praise for the success of friends in finding solutions to problems. Jackson (2001) concluded that group learning improved self-esteem, social behaviour and increased HOTS. In line with this opinion, Charles (2001) found that collaborative learning and active learning play a role in improving problem-solving skills and high-level thinking. According to the results of a metaanalysis of small-group learning conducted by Springer, Stanne, \& Donovan (2007), learning in small groups affects the learning outcomes of group members. Furthermore, studying in groups is also more effective than lecture-based instruction.

CBPS is extremely different from conventional learning where in each student works individually, giving rise to a sense of competition between them. Instead of CBPS, a sense of responsibility arises for the group as a result. Everyone wants to help other group members, and each member contributes to the achievement of group goals. Interpersonal skills are also developed because working in groups involved aspects of communication, leadership, decision making and reflection of the progress that the group has achieved (Tarricone \& Luca, 2002).

Consider to HOTS aspects, prospective teachers have moderate improvement in each aspect except problem solving. The power of problem solving is that gaining a successful solution requires students to refine, relate, and transform knowledge they have already learned (Lester \& Cai, 2016). In this condition, prospective teachers demand to keep practicing on problem solving skills continuously in order to get more experience and challenge to design and modified problem solving strategies.

The results of this study proofs CPBS develop prospective teachers HOTS trough problem solving process. Focusing on problem solving in the classroom not only impacts the development of students' higher-order thinking skills (Lester \& Cai, 2016). Regards of computer technology contribution in visualization, accurate image and Loci, accelerating reasoning, mathematical connection, mathematical communication. Also developing working in groups, provide opportunities to collaborate in conducive environment with joyful and reduces learning anxiety.

\section{CONCLUSION}

Based on the research findings it can be concluded that there is a significant positive effect of CBPS learning methods on the HOTS abilities of prospective teachers. CBPS facilitates thinking skills and the ability in using technology to acquire knowledge and solve problems. Positive influence occurs in all aspects of HOTS except problem solving, which has a very low increase. The implication of the findings of this study is that teachers should prepare a learning plan as well as consider the ability level of prospective teacher students and the level of difficulty of the material. The success of 
CBPS is greatly influenced by problems as a trigger for learning activities. Lecturers need to be careful in determining problems and should pay attention to the difficulty level of the problem. Easy problems will make prospective teachers find the solution directly without exploration first. On the other hand, a difficult problem makes the prospective teachers get cognitive conflict and frustration. The best strategy is to give questions from easy categories to complex ones. Significantly, lecturers should also pay attention to each student's progress.

Future studies are recommended to examine why problem solving abilities of the prospective teachers does not improve like other HOT aspects. This study has limitations in sample size and future studies recommended conduct in large sample size. The focus of this study is only on mathematics subject and expected for next research is to be able to carried out focusing on another subject as well.

\section{REFERENCES}

Arcavi, A., \& Hadas, N. (2000). Computer mediated learning: an example of an approach. International Journal of Computers for Mathematical Learning, 5(1), 25-45. https://doi.org/10.1023/A:1009841817245.

Bukar, I. B., Bello, S., \& Ibi, M. B. (2016). Role of computer in instruction, assessment and administrative delivery of education goals in the university of Maiduguri, Nigeria. Journal of Education and Practice, 7(20), 81-87.

Cañas, A. J., Reiska, P., \& Möllits, A. (2017). Developing higher-order thinking skills with concept mapping: A case of pedagogic frailty. Knowledge Management \& ELearning, 9(3),348-365

Çekmez, E., \& Bülbül, B. Ö. (2018). An example of the use of dynamic mathematics software to create problem-solving environments that serve multiple purposes. Interactive Learning Environments, 26(5), 654-663. https://doi.org/10.1080/10494820.2017.1385029.

Department for Education and Skills (Dfes). (2005). Excellence and enjoyment: Social and emotional aspects of learning: Guidance. London: HMSO http://sealcommunity.org/files/resources/Primary\%20SEAL\%20Guidance\%20English.pdf

Ekstig, K. (2004). Improved understanding in mathematics through computer based problem solving. [Online]. Retrieved from www.vxu.se/msi/picme10/L5EK.pdf.

Glazer, E. (2001). InterMath1-professional and cognitive development through problem solving with technology. Retrieved from http://www.arches.uga.edu/ eglazer/nime2001.pdf

Higgins, S. (2014). Critical thinking for $21^{\text {st }}$ century education: A cyber-tooth curriculum? Prospects, 44(4), 559-574.

Henderson, P. (2017). Computer science, problem solving, and discrete mathematics, (January), 333-342. https://doi.org/10.1090/dimacs/036/28

Hohenwarter, M., \& Fuchs, K. (2004). Combination of dynamic geometry, algebra and calculus in the software system GeoGebra. Combination of dynamic geometry, algebra and calculus. Retrieved from http://www.geogebra.org/publications/pecs_2004.pdf. 
Jonassen, D. H., \& Carr, C. S. (2000). Mindtools: Affording multiple knowledge representations for learning. Mahwah, NJ: Lawrence Erlbaum

Kimmins, D. (1996). Technology in school mathematics: A course for prospective secondary school mathematics teachers. [Online]. Retrieved from http://archives.math.utk.edu/ICTCM/EP-8/C89/MSWord/paper.doc.

Kivunja, C. (2014). Do you want your students to be job-ready with 21 st century skills? Change pedagogies: A pedagogical paradigm shift from Vygotskyian social constructivism to critical thinking, problem solving and Siemens' digital connectivism. International Journal of Higher Education, 3(3), 81-91.

Kuzle, A. (2017). Delving into the nature of problem solving processes in a dynamic geometry environment: Different technological effects on cognitive processing. Technology, Knowledge and Learning, 22(1), 37-64. https://doi.org/10.1007/s10758016-9284-x.

Larwin, K., \& Larwin, D. (2011). A meta-analysis examining the impact of computerassisted instruction on postsecondary statistics education: 40 years of research. Journal of Research on Technology in Education, 43(3), 253-278.

Liu, M. (2005). Motivating students trough problem-based learning. Retrieved from http://library.sullivan.edu/QEC/Problem_Based_Learning/Liu_

NECCOS_handoutMinLiu_RP.pdf.

Lester, F. K., \& Cai, J. (2016). Can mathematical problem solving be taught? Preliminary answers from 30 years of research. In P. Felmer, E. Pehkonen, \& J. Klipatrick (Eds.), Posing and solving mathematical problems (pp.117-135). Springer. https://doi.org/10.1007/978-3-319-28023-3_8.

National Council of Teachers of Mathematics. (2000). Principles and standards for school mathematics. Reston, VA.

Newman, F. M., \& Gary, G. W. (2003). Five standards of authentic instruction. Educational Leadership, 50(7), 8-12.

Passey, D. (2000). Higher order thinking skill. Retrieved from http://www.notherngrid.org/ngflwebsite/hots/HOTSintro.pdf.

Pescador, B. (2014). ¿Hacia una sociedad del conocimiento? Revista Med., 22(2), 6-7. doi: $10.18359 /$ rmed.1194.

Puchta, H. (2012). Developing thinking skills in the young learners' classroom. Retrieved from http://www.herbertpuchta.com/wpcontent/files_mf/1337014114YL_Thinking_booklet.pdf.

Rajendran, N. (2002, June). Using constructivist approach to teach higher-order thinking skills: Transforming teaching practice to facilitate mindful learning. Paper presented at the 10th International Conference on Thinking. Retrieved from http://www.nsrajendran.com/documents/articles/harrogate2002.pdf.

Ranee, S. (2002). Computer based simulations in enhancing higher-order thinking in mathematics. Retrieved from http://math.ecnu.edu.cn/earcome3/sym3 /Earcome3_Selva\%20Ranee_sym3.doc. 
Resnick, L.B. (1987) Education and learning to think. Washington: National Academy.

Roh, K. H., \& Park, H. (2010). A meta-analysis on the effectiveness of computer-based education in nursing. Healthcare Informatics Research, 16(3), 149-157.

Santos, M., Aguero, E., Borbon, A., \& Paez, C. (2003). Students' use of technology in mathematical problem solving: Transforming technological artifacts into mathematical tools. In N. A. Pateman, B. J. Dougherty, \& J. T. Zillox (Eds.), Proceedings of the join meeting of the international group for the psychology of mathematics education and the north American chapter (Vol. 4, pp. 119-126). Hawaii: The University of Hawaii

Soulé, H., \& Warrick, T. (2015). Defining 21st century readiness for all students: What we know and how to get there. Psyc. of Aesthetics, Creativity, and the Arts, 9(2), 178.

Sudibyo, E., Jatmiko, B., \& Widodo, W. (2016). The effectiveness of CBL model to improve analytical thinking skills the students of sport science. Int Edu Stu, 9(4), 195.

Sumarmo, U., \& Nishitani, I. (2010). High level mathematical thinking. Kaname Оsaти Natural Science, 9(8). Retrieved from https://gair.media.gunmau.ac.jp/dspace/bitstream/10087/5130/1/03_Nishitani.pdf

Sung, Y. T., Yang, J. M., \& Lee, H. Y. (2017). The effects of mobile-computersupported collaborative learning: meta-analysis and critical synthesis. Review of Educational Research, 87(4), 768-805.

Tarricone, P., \& Luca, J. (2002). Successful teamwork: A case study. Proceedings of the 25th HERDSA Annual Conference, Perth, Western Australia..

Van Laar, E., van Deursen, A. J., van Dijk, J. A., \& de Haan, J. (2017). The relation between 21st-century skills and digital skills: A systematic literature review. Computers in Human Behavior, 72, 577-588.

Vui, T. (2007). Enhancing classroom communication to develop students' mathematical thinking. Retrieved from http://74.125.155.132/ search?q=cache:CmaHbsBDf1kJ:www.criced.tsukuba.ac.jp/math/apec/apec2008/papers /PDF/21.Tran_Vui_Vietnam.pdf.

Yang, Y. T. C. (2015). Virtual CEOs: A blended approach to digital gaming for enhancing higher order thinking and academic achievement among vocational high school students. Computers \& Education, 81, 281-295.

Yen, T. S., \& Halili, S. H. (2015). Effective teaching of higher order thinking (HOT) in education. The Online Journal of Distance Education and e-Learning, 3(2), 41-47.

Zohar,A. dan Dori, Y.J. (2003). Higher Order Thinking Skill and Low Achieving Students: Are There Mutually Exclusive? [Online]. Retrieved from http://www.cc.gatech.edu/lst/jls/vol12no2.html\#Article1

Zoller, U., \& Pushkin, D. (2007). Matching higher-order cognitive skills (HOGS) promotion goals with problem-based laboratory practice in a freshman organic chemistry course. Chemistry Education Research and Practice, 8(2), 153-171. https://doi.org/10.1039/B6RP90028C. 